\title{
Determinants of emotional exhaustion among nursing workforce in urban Ghana: a cross-sectional study
}

\author{
Collins Atta Poku ${ }^{1 *}$, Ernestina Donkor ${ }^{2}$ and Florence Naab ${ }^{3}$
}

\begin{abstract}
Background: The subject of emotional exhaustion organisations has become important because of the emerging trends in employment and its associated challenges. Unhealthy practice environment is a major threat in the incidence of emotional exhaustion among nurses; and any organisational culture that do not support its personnel has huge burnout costs. The study aimed at assessing rate of emotional exhaustion; determining factors that accounts for it and also ascertaining the coping strategies used by nurses to overcome it in the Ghanaian health care setting.

Methods: A cross-sectional study with a proportionate stratified sampling was used to draw a sample from five health facilities. A standardized questionnaire of Professional Practice Environment Scale of Nursing Work Index, Maslach Burnout Inventory and Coping Scale were used to assess variables under study. The STROBE guidelines were followed in reporting this study.

Results: Out of the 232 registered nurses studied, $91.1 \%$ of them reported experiencing moderate to high rate of emotional exhaustion. The practice environment of the nurses explained $39.6 \%$ of the variance in emotional exhaustion. Emotion-focused and problem-focused approaches were identified to be used by registered nurses to cope with emotional exhaustion.

Conclusion: When appropriate and effective intervention are employed, emotional exhaustion will be reduce and this will enrich the effectiveness of quality care delivery to patients.
\end{abstract}

Keywords: Determinants, Emotional exhaustion, Nursing workforce, Urban Ghana

\section{Background}

The subject of burnout in a form of emotional exhaustion has become imperative in health organizations because of the emerging trends in employment and its related problems. It is been ascertained that unhealthy practice environment such as increased workloads, absurd nursepatient ratios, and scarce human and material resources is a major threat in the well-being of professionals especially

\footnotetext{
*Correspondence: attapokucollins@yahoo.com

${ }^{1}$ Department of Nursing, Kwame Nkrumah University of Science and Technology, Kumasi, Ghana

Full list of author information is available at the end of the article
}

in the incidence of emotional exhaustion among nursing workforce [1-4]; and any organisational culture that does not support its personnel has burnout costs [4]. Emotional exhaustion, which is one of the pillars of 'Burnout Syndrome' is defined as syndrome characterized by losing enthusiasm for work [5-8] and it is conceptualised as a response to a discrepancy between job-related strains and resources that is presented through feelings of emotional fatigue [9]. Emotional exhaustion also presents as a chronic manifestation of somatic and emotional depletion that results from extreme workload and/or personal strains and incessant tension from job [10]. It is

(c) The Author(s). 2020 Open Access This article is licensed under a Creative Commons Attribution 4.0 International License, which permits use, sharing, adaptation, distribution and reproduction in any medium or format, as long as you give appropriate credit to the original author(s) and the source, provide a link to the Creative Commons licence, and indicate if changes were made. The images or other third party material in this article are included in the article's Creative Commons licence, unless indicated otherwise in a credit line to the material. If material is not included in the article's Creative Commons licence and your intended use is not permitted by statutory regulation or exceeds the permitted use, you will need to obtain permission directly from the copyright holder. To view a copy of this licence, visit http://creativecommons.org/licenses/by/4.0/ The Creative Commons Public Domain Dedication waiver (http://creativecommons.org/publicdomain/zero/1.0/) applies to the data made available in this article, unless otherwise stated in a credit line to the data. 
understood to develops from defects in the structural and psychological make-ups in an organisation [11, 12]; and the study of this phenomenon in other jurisdictions among nurses have produced distinctive outcomes that need a critical look.

Among health workers, the nursing workforce is mostly found to report constantly complex intensity of emotional exhaustion. The frequency ranges between 37 and 89\% among nurses in Sub-Saharan Africa (SSA). It is, however, common among Intensive Care Units (ICUs) nurses and those who provide reproductive health services. The resultant consequences are low staff productivity and dissatisfaction of care provided by health caregivers [13, 14]. Within the context of a hospital setting, nurses in various units are duty bound to provide care to patients in settings associated with complex care and impending death. They also face death and grief situations on daily basis, and are at risk of becoming more susceptible to psychological repercussions and stress, frequently occasioning in emotional exhaustion $[15,16]$. Emotional exhaustion of nurses has been identified to increased work-related infections, increased medication error, high incidence of patients' fall, poor nurse-physician relations, low personal accomplishment of the nurse, job dissatisfaction and increased turnover intention $[17,18]$. Burnout at workplace also gives rise to chronic adverse emotions such as anger, anxiety or depression, mental exhaustion, apprehension, low enthusiasm, and absenteeism which certainly endangers not only the nurses own health, but also their patients $[19,20]$.

In low-middle-income countries (LMICs) where nurses undertake their task in unfavourable practice environment (uncomfortable postures, extreme noise intensities, and congested work area), there is moderate to higher dimensions of burnout in the form of emotional exhaustion [21]. This obviously make the responsibility of giving care to patients extra demanding. The interactions between professional's work environment and emotional exhaustion cannot be underestimated; as workplace which boast of quality leadership and nurses' involvement in decisionmaking presents with low levels of exhaustion [22, 23]. Greater autonomy for nurses in respect of adequate staffing and resources and positive nurse-physician relation has also been found to improve this phenomenon; and thus reflects on nurses' job satisfaction and enhanced quality of care to clients [24-26].

With World Health Organization (WHO) report on nursing workforce stating that more nurses are required in attaining satisfactory nurse-patient ratio especially in LMICs [27]; measures are needed to reduce emotional exhaustion among nurses. Potential widening of the disproportion of nurse-patient ratio places huge workload that build continuous psychosomatic stress on nurses in a form of fatigue and emotional exhaustion. In extreme cases, emotional exhaustion is reported to results in work-family conflict for the nurse $[28,29]$.

In SSA, organisational factors (demands from job, control over work, social support, and interpersonal relationships, and change over the role of staff) considerably impact on staff's emotional exhaustion. Most nurses have increased chances of exhaustion relative to other health care providers $[30,31]$. As reported in Switzerland 1:59, Canada 1:106 and United Kingdom 1: 118; there is better efficiency in relation to nurse-patient ratio in high-resource countries compared to reported lower nurse-patient ratio in countries in SSA, with perhaps the exception of South Africa (1:192) and few other countries with encouraging statistics. Evidently, Sudan (1:833), Gambia (1:1111), Rwanda (1:1250) and Mali (1: $1667)$ reported a very low nurse-patient ratio with Senegal (0.3) and Mozambique (0.4) even more frightening. While there has been significant improvement in the nurse-patient ratios in Ghana from 1:1251 in 2012 to 1:542 in 2016, and currently 4.2:1000, much is still needed to increase the nursing workforce in Ghana. With this unsafe nurse-to-patient ratio in most health care facilities in Ghana, the expected result is increased levels of stress among health staff [32]. Overall, the key implication is that most countries in SSA will not be able to attain the WHO's recommendation of nursepatient ratio of 1:300; and thus further increase episodes of emotional exhaustion and decreased quality of care to patients in this part of the world [33-35].

Complains of inadequate recognition from clients and their relations and the larger society as a whole usually serve as the main cause of nurses' emotional exhaustion. Additionally, some health care practitioners also experience emotional exhaustion in a form of despair when their patients relapse or their condition deteriorate despite the amount of time and quality of care provided to them [36]. Importantly, it has been an established fact that challenges of role ambiguity of nurses who are promoted without adequate training on their new roles usually cause an upsurge in job burdens. Such situations increase the amount of work by nurses; and inadequate human and material resources to perform these roles result in emotional exhaustion [37]. Emotional fatigue compromises nursing care; thus delay in the recuperating time of patients and avoidable deaths; and also affect nurses' loyalty to an organisation thereby increasing turnover intentions [38].

Emotional exhaustion among nurses in Ghana has not been given considerable attention, as most studies are directed towards other work-related risks with emphasis placed primarily on healthcare professionals in general. Besides, in circumstances where it has been studied, it is generally restricted to a few categories of nurses; therefore, the trends among the broad segment of nursing 
workforce cannot be evaluated. Additionally, in order to ameliorate the hazards caused by emotional exhaustion, and its compounding effects on job satisfaction, quality nursing care and turnover intention; it would be appropriate for nurse researchers to devote more attention to undertaking studies that will holistically assess this concept. The study therefore, aimed at assessing rate of emotional exhaustion, determining the factors that accounts for it and also ascertaining the coping strategies used to overcome it among Ghanaian nurses.

\section{Methods}

\section{Study settings}

The study was conducted at Sunyani Municipality, which is situated in the middle part of the country. It is the capital of one of the 16 regions in Ghana (Bono Region). Sunyani is an urban district with population of 123,224 . The municipality occupies a land area of 1289 $\mathrm{km}^{2}$, and has hospitals [6], clinics [12], Communitybased Health Planning and Services (CHPs) compound [7], maternity homes [3] and health centers [3]. These facilities provide health services to the population [39]. The facilities in Sunyani Municipality serve as the treatment for inhabitants of Sunyani and adjacent districts and referral center for other facilities in the surrounding regions of Ahafo, Bono East, and Northern part of Ghana. The municipal's nursing workforce stands at 480; and they comprises of all categories of nurses: general nurses, midwives, psychiatric nurses, and other specialist nurses [40].

\section{Study design and sample size}

Quantitative descriptive cross-sectional design was employed to obtain data through standardized questionnaires. Registered nurses from five [5] healthcare facilities in the Sunyani Municipal, Ghana were chosen for the conduct of the study. The population comprised Registered Nurses in the selected facilities, with inclusion criteria being nurses who have worked for at least one-year after qualification from Nursing and Midwifery Council of Ghana and were willing to participate in the study. Registered nurses were excluded if they were on annual leave at the time of the study. Miller and Brewer's mathematical formula $\left(n=\mathrm{N} / 1+\mathrm{Ne}^{2}\right)$ for estimating sample size was used; where $\mathrm{n}$ is the sample size, $\mathrm{N}$ is the total population, and e is the margin of error. In effect, the standard deviation was set at $95 \%$ confidence level with a margin of error of 0.05 . The sample size was increased and rounded up with $10 \%$ of the calculated minimum sample size to take care of non-responses, inappropriately filled and/or missing questionnaires. A total of 250 questionnaires were distributed for the study, however, 232 were completely filled and returned; representing $92.8 \%$ response rate.

\section{Sampling technique}

A proportionate stratified sampling technique was used to obtain the required number of respondents from each of the selected facilities based on the inclusion criteria. Thus, respondents from each stratum were made to randomly pick ballot labelled 'YES' to be selected as part of the study and 'NO' to be excluded from the study. This was done to avoid respondent selection bias.

\section{Data collection}

Self-administered questionnaire was done and the process lasted for 3 weeks (4th April, 2017 - 21st April, 2017). Respondents used approximately $30 \mathrm{~min}$ to fill the questionnaire. Standardized tools were adapted for the study of the various variables. The Professional Practice Environment was measured using the "Practice Environment Scale of Nursing Work Index (PES-NWI)" developed by Lake (2002) [41]. The tool is made up of 5 sub-scales (nurse manager ability, leadership and support, collegial nurse-physician relations, staffing and resource adequacy, nurse participation in hospital affairs and nursing foundations for quality care) with sum of 32 items on a four Likert scale 1-4 (1 = strongly disagree; $4=$ strongly agree) was used to measure PPE. The total score for Professional Practice Environment is the sum of all 32 items with a range of 32 to 128 . Scores between 1 and 32 indicated poor practice environment; a score between 33 and 85 showed moderate practice environment while scores above 85 showed good practice environment. Most studies have used this scale and it has proven satisfactory reliability $[42,43]$. The emotional exhaustion dimension of the "The Maslach Burnout Inventory (MBI)" Scale developed by Maslach, Jackson, and Leiter (1981) was used to measure emotional exhaustion of nurses. It is made up of 9 items and measured on a seven Likert scale $(0=$ Never; $6=$ Everyday $) . \quad$ Items summed and averaged to provide emotional exhaustion score. A score of 0 to 16,17 to 26 , and 27 and above indicated low, moderate and high emotional exhaustion respectively. Earlier studies which used the MBI demonstrated acceptable Cronbach's alpha [44]. Coping strategies used by nurses were measured using the "Coping Scale" [45]. It is measured on a four Likert scale $(4=$ Mostly true about me; 1 = Not true about me); and made up of 13 items. Higher scores indicate higher level of coping. The scale has a reliability of 0.69 [46].

In order to validate the tool, a pre-test of the standardised questionnaire was conducted on 20 nurses from SDA Hospital-Sunyani who met the inclusion criteria, and it yielded reliability of 0.86 . This exercise was done to ascertain the appropriateness of the questionnaire, whether it is difficult to understand or whether questionnaire contained culturally insensitive questions. To ensure reliability of the tool, the various part of the 
questionnaire was adapted except socio-demographic data. The Cronbach's alpha for the scale was estimated as 0.86 after the test with component subscales as follows: PES-NWI - 0.88, MBI - 0.90 and Coping Scale of 0.74, all considered standard [47].

\section{Ethical approval and consent to participate}

An ethical clearance was sought from the Noguchi Memorial Institute for Medical Research Institutional Review Board -IRB with number CPN 045/16-17 while respondents also gave verbal consent prior to data collection as approved by the IRB. Verbal consent was used as most participants were skeptical about undertaking written consent. The benefits and possible risks were also explained to respondents. Additionally, respondents' anonymity and confidentiality were assured by indicating that they were not required to write their name on the questionnaire and by assuring them that their responses will not in any way be linked to them. Respondents were told that participation was voluntary and that they were free not to respond to questions they did not want. They were also informed that the completion of the questionnaire indicated explicit consent to use the data for research purposes.

\section{Data analysis}

Statistical Package for Social Sciences (SPSS), version 23.0 was used for the data analysis. Descriptive statistics (means, frequencies and standard deviations) were used to summarise the variable of interest. Pearson correlation analysis was conducted to determine the relationship between professional practice environment and emotional exhaustion while the two models of multiple regression analysis was used to determine the predictors of emotional exhaustion of nurses. Also, mean and standard deviation were used to analyse the coping strategies used by nurses. Data analysis was conducted at a significance level of 0.05 and power of $95 \%$.

\section{Results}

\section{Socio-demographic characteristics}

The socio-demographic characteristics of the 232 respondents are presented in Table 1 below. The study showed majority of registered nurses $(62.1 \%)$ were between the ages of 26 and 35 years, with the mean age of $29.13(\mathrm{SD}=5.061)$. Approximately $71 \%(n=164)$ were females, about half of them (50.4\%) were married while 191 (82.3\%) had diploma in nursing education. The average working years for the respondents was 3.71 with most of them $(83.6 \%, n=194)$ having worked for a period of 1 to 6 years. In addition, 34\% $(n=79)$ of the nurses worked at the Medical/Surgical Units, and more than half $(56.6 \%)$ of the respondents were staff nurses. Most of the nurses (47.8\%) attend 8-h shift duty. The mean score for emotional exhaustion was high (mean = $31.24, \quad \mathrm{SD}=13.29)$; correspondingly most respondents (91.1\%, $n=209)$ experienced moderate to high forms of emotional exhaustion at work.

Table 2 above presents the correlation between selected demographic information, facets of practice environment and emotional exhaustion of registered nurses. The highest qualification of the nurse and all the facets of professional practice environment had significant negative correlations $(p<0.05)$ with emotional exhaustion as follow: highest qualification of the nurse $(r=$ $-.185)$, nursing foundation for quality of care $(r=-.259)$, staffing and resource adequacy $(r=-.517)$, nurse manager ability, leadership and support $(r=-.164)$, collegial nurse-physician relation $(r=-.243)$ and nurse participation in hospital affair $(r=-.538)$.

Table 3 above shows the multiple linear regression model for the predictors of emotional exhaustion of nurses. In model 1, the results showed that the sociodemographic characteristics of nurses accounted for $28.1 \%$ variances of emotional exhaustion in nurses, with highest qualification $(B=-.273, p=.000)$, years in nursing $(B=.223, p=.020)$ and current rank of nurses $(B=-$ .337, $p=.000)$ being significant predictors. In the final model, professional practice environment variables were entered explaining an additional $11.5 \%$ of the variance in emotional exhaustion. In the final model, all variables were significant predictors of emotional exhaustion explaining $39.6 \%$ of the variation (Adjusted $R^{2}=.396$, $F=14.510, p=.000)$. Nurse manager ability, leadership and support $(B=-.132, p=.023)$, collegial nursephysician relations $(B=.205, p=.022)$, staffing and resource adequacy $(B=-0.212, p=.012)$, and nurses participation in hospital affair $(B=-.270, p=.001)$ were important predictors of emotional exhaustion although they differed in their effect.

\section{Coping strategies used by nurses}

The means and standard deviations for coping strategies used by nurses during emotional exhaustion are found in Table 4 below. Nurses reported high usage of the following strategies; 'I consider several alternatives for handling the problem' (mean $=3.258$ ), 'I often try to remember that the problem is not as serious as it seems' (mean $=3.163)$, 'I take steps to take better care of myself and my family for the future' (mean $=3.150$ ), I make jokes about it or try to make light of it' (mean =3.142), 'I try to see the positive side of the situation' (mean = 3.137), 'I make compromises' (mean $=3.099$ ) 'I often use exercise, hobbies, or meditation to help me get through a tough time' (mean =3.094), and 'I think about what it might say about bigger lifestyle changes I need to make' $($ mean $=3.081)$. 
Table 1 Socio-demographic characteristics of respondents

\begin{tabular}{|c|c|c|}
\hline Variable $(N=232)$ & Frequency (n) & Percent (\%) \\
\hline \multicolumn{3}{|l|}{ Age of respondent } \\
\hline $18-25$ & 59 & 25.4 \\
\hline $26-35$ & 144 & 62.1 \\
\hline $36-45$ & 25 & 10.8 \\
\hline $45-59$ & 4 & 1.7 \\
\hline \multicolumn{3}{|l|}{ Gender } \\
\hline Male & 68 & 29.3 \\
\hline Female & 164 & 70.7 \\
\hline \multicolumn{3}{|l|}{ Marital status } \\
\hline Single & 113 & 48.7 \\
\hline Married & 117 & 50.4 \\
\hline Separated & 2 & 0.9 \\
\hline \multicolumn{3}{|l|}{ Educational Qualification } \\
\hline Diploma & 191 & 82.3 \\
\hline Bachelor & 33 & 14.2 \\
\hline Masters & 8 & 3.4 \\
\hline \multicolumn{3}{|l|}{ Years in Nursing } \\
\hline 1-3 year & 106 & 45.7 \\
\hline v4-6 years & 88 & 37.9 \\
\hline 7-10 years & 24 & 10.3 \\
\hline More than 10 years & 14 & 6.0 \\
\hline \multicolumn{3}{|l|}{ Years in the hospital } \\
\hline 1-3 year & 104 & 44.8 \\
\hline $4-6$ years & 98 & 42.2 \\
\hline 7-10 years & 22 & 9.6 \\
\hline More than 10 years & 8 & 3.4 \\
\hline \multicolumn{3}{|l|}{ Area of work in hospital } \\
\hline Critical care/Emergency & 38 & 20.7 \\
\hline Medical unit & 46 & 19.8 \\
\hline Surgical unit & 33 & 14.2 \\
\hline Obstetrics & 31 & 13.4 \\
\hline Pediatric & 28 & 12.1 \\
\hline Theatre/ICU & 17 & 7.3 \\
\hline Orthopedics & 6 & 2.6 \\
\hline Mental Health/Psychiatry & 14 & 6.0 \\
\hline Others & 9 & 3.9 \\
\hline \multicolumn{3}{|l|}{ Current rank of respondent } \\
\hline Staff Nurse/Midwives & 131 & 56.6 \\
\hline Head nurse & 59 & 25.4 \\
\hline Charge nurse & 26 & 11.2 \\
\hline Supervisor & 13 & 5.6 \\
\hline Directors & 1 & 0.4 \\
\hline Others & 2 & 0.9 \\
\hline
\end{tabular}

Type of shift system by respondent
Table 1 Socio-demographic characteristics of respondents (Continued)

\begin{tabular}{lll}
\hline Variable $(\boldsymbol{N}=\mathbf{2 3 2})$ & Frequency $\mathbf{( n )}$ & Percent (\%) \\
\hline $\mathbf{8 h}$ & $\mathbf{1 1 1}$ & $\mathbf{4 7 . 8}$ \\
$12 \mathrm{~h}$ & 15 & 6.5 \\
Both 8 and 12 h & 106 & 45.7 \\
Emotional Exhaustion of Nurses & & \\
Low & 23 & 9.9 \\
Moderate & $\mathbf{1 2 5}$ & $\mathbf{5 3 . 9}$ \\
High & 84 & 36.2 \\
Emotional Exhaustion of Nurses & $\mathbf{M e a n}$ & $\mathbf{S D}$ \\
& 31.24 & 13.29 \\
\hline Source: Field
\end{tabular}

Source: Field Data (2017)

\section{Discussion}

The study aimed at assessing rate of emotional exhaustion at the practice environment, establishing it determinants and the coping strategies used by nurses to overcome it. It was done among various categories of nursing staff. Most practice environments present occupational threats to the nurse; among factors accounting for such threats are undesirable experience from discomfort and death of patients, conflicts with colleagues and other health professionals, and the absence of support from nurse managers. The nursing profession has therefore been categorised as a risk job for burnout (emotional exhaustion). The study reported higher level of emotional exhaustion (mean $=31.244)$ with most nurses $(n=209,90.1 \%)$ affirming it as indicated in Table 1. Similar studies undertaken at the Sub-Saharan African regions posit that high rates of burnout in a form of emotional exhaustion among nurses and midwives; and are usually attributed to work environments, work conflicts, and lack of social support [31, 47] Other researchers found emotional exhaustion among nurses working in health care facilities in South Africa [48], Ethiopia [49] and Nigeria [50]. It is well established that job stresses results from unsupportive practice environment, and it may affect the nurses' satisfaction, turnover intentions and the quality of care delivery to patients [51]. The high incidence of emotional exhaustion (90.1\%) is consistent with happening in health facilities as most nurses are exposed to stressful challenges in the course of their work such as providing palliative care to end-of-life stages of patients, as well as managing grieving process during death of patient. Again, extremely huge workloads from ones job as a result of the unsupportive work environment can also account for this phenomenon [51, 52]. In other settings, it is reported that high level of abuse from patients and their relatives and some senior members of the health team, dissatisfaction with salaries, limited opportunities for professional improvement and inadequate nurses' participation 
Table 2 Correlation between selected variables and emotional exhaustion

\begin{tabular}{|c|c|c|c|c|c|c|c|c|c|c|c|c|}
\hline Variables & EE & A & $\mathrm{H}$ & YN & YH & C & NMLS & NPR & NPHA & SRA & NFQC & PES \\
\hline Emotional Exhaustion (EE) & 1 & .010 & $-.185^{* *}$ & -.003 & .002 & .066 & $-.164^{*}$ & $-.243^{* *}$ & -.538 & $-.517^{* *}$ & $-.259^{* *}$ & $-.338^{* *}$ \\
\hline Age of nurse $(A)$ & .010 & 1 & $.652^{* *}$ & $.968^{* *}$ & $.935^{* *}$ & $.486^{* *}$ & .034 & .027 & .060 & .033 & -.051 & .008 \\
\hline Highest qualification $(\mathrm{H})$ & $-.185^{*}$ & $.652^{* *}$ & 1 & $.660^{* *}$ & $.614^{* *}$ & $.404^{* *}$ & .118 & $.232^{* *}$ & .104 & $.242^{* *}$ & $.165^{*}$ & $.237^{* *}$ \\
\hline Years in Nursing (YN) & -.003 & $.968^{* *}$ & $.660^{* *}$ & 1 & $.954^{* *}$ & $.479^{* *}$ & .040 & .031 & .044 & .027 & -.060 & .010 \\
\hline Years in hospital $(\mathrm{YH})$ & .002 & $.935^{* *}$ & $.614^{* *}$ & $.954^{* *}$ & 1 & $.484^{* *}$ & .069 & .042 & .051 & .039 & -.062 & .018 \\
\hline Current rank of nurse $(\mathrm{C})$ & .066 & $.486^{* *}$ & $.404^{* *}$ & $.479^{* *}$ & $.484^{* *}$ & 1 & -.072 & .055 & .026 & .029 & -.068 & .010 \\
\hline $\begin{array}{l}\text { Nurse Manager Ability Leadership \& Support } \\
\text { (NMALS) }\end{array}$ & $-.164^{*}$ & .034 & .118 & .040 & .069 & -.072 & 1 & $.367^{* *}$ & .075 & $.359^{* *}$ & $.280^{* *}$ & $.382^{* *}$ \\
\hline Nurse-Physician Relation (NPR) & $-.243^{* *}$ & .027 & $.232^{* *}$ & .031 & .042 & .055 & $.367^{* *}$ & 1 & $.409^{* *}$ & $.892^{* *}$ & $.749^{* *}$ & $.936^{* *}$ \\
\hline Nurses' Participation in Hospital Affairs (NPHA) & $-.538^{* *}$ & .060 & .104 & .044 & .051 & .026 & .075 & $.409^{* *}$ & 1 & $.464^{* *}$ & $.380^{* *}$ & $.468^{* *}$ \\
\hline Staffing and Resource Adequacy (SRA) & $-.517^{* *}$ & .033 & $.242^{* *}$ & .027 & .039 & .029 & $.359^{* *}$ & $.892^{* *}$ & $.464^{* *}$ & 1 & $.801^{* *}$ & $.949^{* *}$ \\
\hline Nursing Foundation for Quality Care (NFQC) & $-.295^{* *}$ & -.051 & $.165^{*}$ & -.060 & -.062 & -.068 & $.280^{* *}$ & $.749^{* *}$ & $.380^{* *}$ & $.801^{* *}$ & 1 & $.861^{* *}$ \\
\hline Nursing Practice Environment (NPE) & $-.338^{* *}$ & .008 & $.237^{* *}$ & .010 & .018 & .010 & $.382^{* *}$ & $.936^{* *}$ & $.468^{* *}$ & $.949^{* *}$ & $.861^{* *}$ & 1 \\
\hline
\end{tabular}

${ }^{* * *}$ Correlation is significant at $p<0.01$ level (2-tailed). ${ }^{*}$ Correlation is significant at $p<0.05$ level

"Nurse Manager Ability, Leadership and Support, Nurse-Physician Relation, Nurses' Participation in Hospital Affairs, Staffing and Resource Adequacy, and Nursing Foundation for Quality Care" are sub-scales of PES-NWI

in decision making in the hospital account for increased pace of emotional exhaustion among nurses; as these factors devalue the role nurses play in the health care set-up and this can affect them emotionally $[9,53,54]$. Though, much has not been done to curtail emotional exhaustion among nurses in Ghana, effective leadership from nurse managers, monetary compensation from employers [55] and dynamic support from co-workers on daily basis at work place [35] can efficiently decrease this dimension of burnout among nurses in the near future.

The results support the fact that socio-demographic characteristics and facets of professional practice environment of nurses together are predictive of emotional exhaustion (adjusted $R^{2}=0.396$ ). Regular upgrade of nurses through promotion to higher grades and ensuring nurses' professional practice environment are vital to developing resilience in managing emotional exhaustion at the work place [56-58].

Additionally, nurses' perceptions of emotional exhaustion are affected by staffing and resource adequacy in the work place $(B=-0.212)$, suggesting that improving staffing and resources in the hospital can reduce emotional exhaustion of nurses by almost third through improving the quantity and quality of nursing human resources and medical equipment used in managing patients. Our findings are consistent with $[59,60]$ who concluded that poor staffing and resource inadequacy in practice environment are associated with emotional exhaustion of nurses. Institutional policies to enhance adequate staffing and material resources aimed at improving the welfare of nursing staff will have a very important role in reducing emotional exhaustion.

Nursing as a profession expects participation and greater capacity in decision-making in the clients' care delivery. Therefore, cultivating the spirit of teamwork between health professionals and involving nurses in the management of the health facility would go a long way to eradicate emotional exhaustion and also increase nurses' self-esteem in health care settings. The current study also found nurse participation in hospital affairs to be significantly predicted with emotional exhaustion $(B=-0.270)$. This is consistent with a study which identified that nurses demonstrate more confident when they are involved in collective decision making in health facilities, more so when their professional roles are recognized. Again, work place where nurses and other health professional mutually perform their roles advertently provides foundation for teamwork and enhanced job outcomes [61]. Nurses' emotional exhaustion can lead to an upsurge of scarcity of nurses, and the consequent poor nursing care delivery to patients. It is, therefore, imperative and critical for health care managers to tackle issues of nurses' involvement in hospital affairs.

Emotional exhaustion is high in work environment where nurses perceive that their nurse manager are not able to provide adequate leadership and support $(B=-$ 0.132) for advancement of the nursing profession. Poor perception of the nurse manager ability, leadership and support for nurses corresponds with increase in rates of emotional exhaustion among nurses, as support for most of the stresses nurse encounter is limited. As noted by [62], nursing leadership is valued and respected by subordinates as they expect a great deal of support from their leadership. When nursing leaders fail in their role at influencing nurses' daily work practice and promoting their welfare through the creation of a positive practice environment; there is always emotional strains on nurses. It is imperative that health facilities find effective 
Table 3 Multiple linear regression models for predictors of emotional exhaustion

\begin{tabular}{|c|c|c|c|c|c|}
\hline \multirow[t]{2}{*}{ Model } & \multicolumn{2}{|c|}{ Unstandardized Coefficients } & \multirow{2}{*}{$\begin{array}{l}\text { Standardized Coefficients } \\
\text { Beta }\end{array}$} & \multirow[t]{2}{*}{$T$} & \multirow[t]{2}{*}{ Sig. } \\
\hline & $\bar{B}$ & SE & & & \\
\hline \multicolumn{6}{|l|}{ Model 1} \\
\hline (Constant) & 17.563 & 9.725 & & 1.806 & .072 \\
\hline Age of nurse & .528 & .415 & .219 & 1.273 & .204 \\
\hline Highest qualification of nurse & -4.063 & 1.046 & -.273 & -3.884 & .000 \\
\hline Years in Nursing & .595 & .253 & .223 & 2.350 & .020 \\
\hline Number of years in hospital & -.779 & .636 & -.196 & -1.225 & .222 \\
\hline Current rank of nurse & -2.832 & .566 & -.337 & -5.004 & .000 \\
\hline \multicolumn{6}{|c|}{ Model 1 Summary: $\mathrm{R}^{2}=.281, \mathrm{~F}={ }_{(5,226)}=17.622, p=.000$} \\
\hline \multicolumn{6}{|l|}{ Model 2} \\
\hline (Constant) & 44.309 & 10.146 & & 4.367 & .000 \\
\hline Age of nurse & .309 & .387 & .128 & .797 & .427 \\
\hline Highest qualification of nurse & -2.276 & 1.019 & -.153 & -2.233 & .027 \\
\hline Years in Nursing & .381 & .249 & .143 & 1.531 & .127 \\
\hline Number of years in hospital & -.536 & .600 & -.135 & -.894 & .372 \\
\hline Current rank of nurse & -1.276 & .620 & -.152 & -2.057 & .041 \\
\hline Nurse Manager's Ability, Leadership \& Support & -.206 & .090 & -.132 & -2.289 & .023 \\
\hline Collegial Nurse-Physician Relations & .415 & .180 & .205 & 2.302 & .022 \\
\hline Nursing Foundations for Quality of Care & -.409 & .324 & -.103 & -1.264 & .208 \\
\hline Staffing and Resource Adequacy & -.461 & .181 & -.212 & -2.543 & .012 \\
\hline Nurse Participation in Hospital Affairs & -1.529 & .434 & -.270 & -3.524 & .001 \\
\hline \multicolumn{6}{|c|}{ Model 2 Summary: $R^{2}=.396, F={ }_{(10,221)}=14.510, p=.000$} \\
\hline
\end{tabular}

Outcome: Emotional Exhaustion, 95\% confidence level $(\alpha=.05)$

Table 4 Coping strategies used by nurses

\begin{tabular}{|c|c|c|c|c|}
\hline Coping Strategy & Min. & Max. & Mean & SD \\
\hline I spend time trying to understand what happened & 1.00 & 4.00 & 1.840 & .860 \\
\hline I try to see the positive side of the situation. & 1.00 & 4.00 & 3.137 & .731 \\
\hline I try to step back from the problem and think about it from a different point of view. & 1.00 & 4.00 & 1.879 & .874 \\
\hline I consider several alternatives for handling the problem. & 1.00 & 4.00 & 3.258 & .652 \\
\hline I try to see the humor in it. & 1.00 & 4.00 & 1.745 & .827 \\
\hline I think about what it might say about bigger lifestyle changes I need to make. & 1.00 & 4.00 & 3.081 & .748 \\
\hline I often wait it out and see if it doesn't take care of itself. & 1.00 & 4.00 & 1.870 & .868 \\
\hline I often try to remember that the problem is not as serious as it seems. & 1.00 & 4.00 & 3.163 & .714 \\
\hline I often use exercise, hobbies, or meditation to help me get through a tough time. & 1.00 & 4.00 & 3.094 & .749 \\
\hline I make jokes about it or try to make light of it. & 1.00 & 4.00 & 3.142 & .715 \\
\hline I make compromises. & 1.00 & 4.00 & 3.099 & .734 \\
\hline I take steps to take better care of myself and my family for the future. & 1.00 & 4.00 & 3.150 & .713 \\
\hline $\begin{array}{l}\text { I work on making things better for the future by changing my habits, such as } \\
\text { diet, exercise, budgeting, or staying in closer touch with people I care about }\end{array}$ & 1.00 & 4.00 & 1.754 & .824 \\
\hline
\end{tabular}


approaches to advancing the development and retention of experienced nurse manager to enhance implementation of mechanisms to reduce emotional exhaustion among nurses.

It is an established fact that positive nurse-physician relation at health facilities produces better outcomes for the nurse [63]. A negative correlation was found between nurse-physician relation and emotional exhaustion. It is significant for health care managers, physicians and nurses to ensure efficient communication, mutual support and readiness to compromise having an insightful outcome on teamwork between players in the health care setting. The need to develop ways of building professional respect for team players, promoting productive contact between nurses and physicians and increasing the ability of nursing staff to participate in decision making can go a long way to reduce emotional exhaustion at the work place.

The findings of this study are similar with [64], which suggested the use of a positive coping approach in the form of positive re-appraisal and firmness by attempting to see positive aspects of every challenge and also anxiety reduction approaches by performing recreational activities as remedies for successful stress management. Participating in leisure activities and having an active social life and conversation with relations, friends and peers relieve stress while also elevating the individual's mood to confront the challenges encountered. As reported, conflict resolution tool of 'compromise' was also identified as a means of addressing the emotional exhaustion arising from workplace conflict [65]; and this position is consistent with the study findings. It is significant to note that in order to effectively cope with emotional exhaustion at the workplace, the use of both emotion-focused (e.g. reduction of anxiety and positive re-appraisal) and problem-focused approaches (communicating feeling and support, finding alternative reinforcement) cannot be overlooked. In essence, nurses and nurse managers should identify the best available interventions to mitigate emotional exhaustion in course of their duty.

\section{Study limitations}

The results cannot be generalised to other environments and territories as only five [5] health facilities were used. As with any research study, bias in response can affect the validity of the findings. Our response rate of $92.8 \%$, however, is much higher than that recorded in most nursing surveys, reducing the potential for non-response bias to misrepresent our study findings.

\section{Conclusions}

With far more than $90 \%$ of registered nurses experiencing moderate to high emotional exhaustion; it may compromise the quality care of patient. Initiatives such as improved support from nurse manager and good relationship between nurse and physician can positively minimize this phenomenon among nurses. It is also necessary to assess nursing staff' workload in order to significantly reduce nurses' emotional exhaustion related to their job-demand and also commit sufficient resources in the training of lower-ranking nurses on how to deal with emotional exhaustion. In an attempt to lessen emotional exhaustion, nurse managers should be accountable for ensuring and promoting reasonable safety in and out of the work environment. Analysing and mitigating risks measures in the sense of organizational structure is essential in building healthy nursing work environments. Furthermore, coping mechanisms when implemented on time can directly influence the interaction between the professional practice environment and the emotional exhaustion of nurses. Thus, when appropriate and effective intervention are employed, emotional exhaustion will be reduce and this will help enrich the quality of care delivered to patients.

\section{Abbreviations \\ CHPS: Community-based Health Planning and Services; GHS: Ghana Health Service; ICUs: Intensive Care Units; LMICs: Low-middle-income countries; IRB: Institutional Review Board; MBI: Maslach Burnout Inventory; PES- NWI: Practice Environment Scale of Nursing Work Index; SDA: Seventh Day Adventist; SSA: Sub-Saharan Africa; WHO: World Health Organization}

\section{Acknowledgements}

The authors wish to sincerely thank all Registered Nurses who participated in the study.

\section{Authors' contributions}

CAP, ED and FN conceptualized and designed the study method. CAP and FN carried out the data collection, analysis and interpretation of data. CAP originally drafted the manuscript. All authors read, revised and approved the final manuscript for submission.

\section{Funding}

No funding was received for this study.

\section{Availability of data and materials}

The datasets used and/or analysed during the current study are presented within the manuscript and have also been added as supporting files.

\section{Ethics approval and consent to participate}

An ethical clearance was sought from the Noguchi Memorial Institute for Medical Research Institutional Review Board -IRB with number CPN 045/1617 while respondents also gave verbal consent prior to data collection as approved by the IRB. Verbal consent was used as most participants were skeptical about undertaking written consent. Clearance was obtained from the Ghana Health Service (GHS) Regional Health Directorate (Brong Ahafo) before the commencement of the study.

\section{Consent for publication}

Not Applicable.

\section{Competing interests}

The authors declare that they have no competing interests.

\section{Author details}

'Department of Nursing, Kwame Nkrumah University of Science and Technology, Kumasi, Ghana. ${ }^{2}$ School of Nursing and Midwifery, University of Health and Allied Sciences, Ho, Ghana. ${ }^{3}$ School of Nursing and Midwifery, University of Ghana, Legon-Accra, Ghana. 
Received: 17 August 2020 Accepted: 1 December 2020 Published online: 07 December 2020

\section{References}

1. dos Santos Alves DF, da Silva D, de Brito Guirardello E. Nursing practice environment, job outcomes and safety climate: a structural equation modelling analysis. J Nurs Manag. 2017;25(1):46-55. https://doi.org/10.1111/ jonm.12427.

2. Rivaz M, Momennasab M, Yektatalab S, Ebadi A. Adequate resources as essential component in the nursing practice environment: a qualitative study. J Clin Diagn Res. 2017;11(6):IC01. https://doi.org/10.7860/JCDR/2017/ 25349.9986.

3. Ducharme MP, Bernhardt JM, Padula CA, Adams JM. Leader influence, the professional practice environment, and nurse engagement in essential nursing practice. J Nurs Adm. 2017;47(7/8):367-75. https://doi.org/10.1097/ NNA.0000000000000497.

4. Falquera CC, los Santos JAA D, Galabay JR, Firmo CN, Tsaras K, Rosales RA, et al. Relationship between nurse practice environment and work outcomes: A survey study in the Philippines. Int J Nurs Pract. 2020:e12873. https://doi.org/10.1111/ijn.12873.

5. Hewitt DB, Ellis RJ, Hu Y-Y, Cheung EO, Moskowitz JT, Agarwal G, et al. Evaluating the Association of Multiple Burnout Definitions and Thresholds with Prevalence and outcomes. JAMA Surg. 2020. https://doi.org/10.1001/ jamasurg.2020.3351.

6. Moukarzel A, Michelet P, Durand A-C, Sebbane M, Bourgeois S, Markarian T, et al. Burnout syndrome among emergency department staff: prevalence and associated factors. Biomed Res Int. 2019;2019. https://doi.org/10.1155/ 2019/6462472

7. Arrogante O, Aparicio-Zaldivar E. Burnout and health among critical care professionals: the mediational role of resilience. Intensive Crit Care Nurs. 2017:42:110-5. https://doi.org/10.1016/j.iccn.2017.04.010.

8. Rotenstein LS, Torre M, Ramos MA, Rosales RC, Guille C, Sen S, et al. Prevalence of burnout among physicians: a systematic review. JAMA. 2018; 320(11):1131-50. https://doi.org/10.1001/jama.2018.12777.

9. Lahana E, Papadopoulou K, Roumeliotou O, Tsounis A, Sarafis P, Niakas D. Burnout among nurses working in social welfare centers for the disabled. BMC Nurs. 2017:16(1):15. https://doi.org/10.1186/s12912-017-0209-3.

10. Choi B-S, Kim JS, Lee D-W, Paik J-W, Lee BC, Lee JW, et al. Factors associated with emotional exhaustion in south korean nurses: a cross-sectional study. Psychiatry Invest. 2018;15(7):670. https://doi.org/10.30773/pi.2017.12.31.

11. Fennessey AG. The relationship of burnout, work environment, and knowledge to self-reported performance of physical assessment by registered nurses. Medsurg Nurs. 2016;25(5):346.

12. Mendelsohn D, Despot I, Gooderham PA, Singhal A, Redekop GJ, Toyota BD. Impact of work hours and sleep on well-being and burnout for physiciansin-training: the resident activity tracker evaluation study. Med Educ. 2019; 53(3):306-15. https://doi.org/10.1111/medu.13757.

13. Filho FA, Rodrigues MCS, Cimiotti JP. Burnout in Brazilian intensive care units: a comparison of nurses and nurse technicians. Adv Crit Care. 2019; 30(1):16-21. https://doi.org/10.4037/aacnacc2019222.

14. Purpora C, Cooper A, Sharifi C, Lieggi M. Workplace bullying and risk of burnout in nurses: a systematic review protocol. JBI Evid Synthesis. 2019; 17(12):2532-40. https://doi.org/10.11124/JBISRIR-D-19-00019.

15. Block RI, Bair HL, Carillo JF Is exhaustion more sensitive than disengagement to burnout in academic anesthesia? A study using the Oldenburg burnout inventory. Psychol Rep. 2020;123(4):1282-96. https://doi. org/10.1177/0033294119856560.

16. Akkoç I, Okun O, Türe A. The effect of role-related stressors on nurses' burnout syndrome: the mediating role of work-related stress. Perspect Psychiatr Care. 2020. https://doi.org/10.1111/ppc.12581

17. Balducci C, Alessandri G, Zaniboni S, Avanzi L, Borgogni L, Fraccaroli F. The impact of workaholism on day-level workload and emotional exhaustion, and on longer-term job performance. Work Stress. 2020:1-21. https://doi. org/10.1080/02678373.2020.1735569.

18. Baeriswyl S, Krause A, Elfering A, Berset M. How workload and coworker support relate to emotional exhaustion: the mediating role of sickness presenteeism. Int J Stress Manag. 2017;24(S1):52. https://doi.org/10.1037/ str0000018.

19. Boamah SA, Read EA, Spence Laschinger HK. Factors influencing new graduate nurse burnout development, job satisfaction and patient care quality: a time-lagged study. J Adv Nurs. 2017;73(5):1182-95. https://doi.org/ 10.1111/jan.13215

20. Liu J, Zheng J, Liu K, Liu X, Wu Y, Wang J, et al. Workplace violence against nurses, job satisfaction, burnout, and patient safety in Chinese hospitals. Nurs Outlook. 2019;67(5):558-66. https://doi.org/10.1016/j.outlook.2019.04.006.

21. Dugani S, Afari $H$, Hirschhorn LR, Ratcliffe H, Veillard J, Martin G, et al. Prevalence and factors associated with burnout among frontline primary health care providers in low-and middle-income countries: a systematic review. Gates Open Res. 2018;2. https://doi.org/10.12688/gatesopenres. 12779.3.

22. Van Bogaert P, Clarke S. Concepts: organization of nursing work and the psychosocial experience of nurses. In: The Organizational Context of Nursing Practice. Springer; 2018. p. 5-47.

23. Lee H-F, Chiang H-Y, Kuo H-T. Relationship between authentic leadership and nurses' intent to leave: the mediating role of work environment and burnout. J Nurs Manag. 2019;27(1):52-65. https://doi.org/10.1111/jonm. 12648.

24. Malik N, Dhar RL. Authentic leadership and its impact on extra role behaviour of nurses. Person Rev. 2017. https://doi.org/10.1108/PR-05-2015-0140.

25. van Oostveen $\mathrm{C}$, Vermeulen $\mathrm{H}$. Greater nurse autonomy associated with lower mortality and failure to rescue rates. Evid -Based Nurs. 2017;20(2):56. https://doi.org/10.1136/eb-2016-102591.

26. Guirardello E de B. Impact of critical care environment on burnout, perceived quality of care and safety attitude of the nursing team. Revista Latino-Americana Enfermagem. 2017;25. doi: https://doi.org/10.1590/15188345.1472.2884

27. Mtega B, Kibona L, Dhamani K, Petrucka P. Perceptions of nurses on patient outcomes related to nursing shortage and retention strategies at a public hospital in the coastal region of Tanzania. Open J Nurs. 2017;7(9):1044-57. https://doi.org/10.4236/ojn.2017.79076.

28. Taleghani F, Ashouri E, Memarzadeh M, Saburi M. Barriers to empathy-based care: oncology nurses' perceptions. Int J Health Care Qual Assur. 2018. https://doi.org/10.1108/IJHCQA-12-2016-0185.

29. Galletta M, Portoghese I, Melis P, Gonzalez CIA, Finco G, D'Aloja E, et al. The role of collective affective commitment in the relationship between workfamily conflict and emotional exhaustion among nurses: a multilevel modeling approach. BMC Nurs. 2019;18(1):1-9. https://doi.org/10.1186/ s12912-019-0329-z.

30. Agyapong A, Osei HV, Essuman D. Re-examining the link between occupational stress and burnout in a sub-Saharan African nation: the precursor and moderating roles of organisational and social support. Int J Bus Excell. 2019;17(4):414-38. https://doi.org/10.1504/IJBEX.2019.099121.

31. Dubale BW, Friedman LE, Chemali Z, Denninger JW, Mehta DH, Alem A, et al. Systematic review of burnout among healthcare providers in subSaharan Africa. BMC Public Health. 2019;19(1):1247. https://doi.org/10.1186/ s12889-019-7566-7.

32. Ofori-Atta A, Jack H. Dilemmas of healthcare professionals in Ghana. Changing Trends Ment Health Care Res Ghana. 2015;2:244-54.

33. Abejide Leo, Tasi'u M, Ogah Hi. Inequality in Global Distribution of Skilled Health Personnel: A Health-Related Disaster to Achieving SDG 3 in SubSaharan Africa. Afr J Soc Sci Human Res. 2020;3(5):21-40.

34. Peters A, Palomo R, Pittet D. The great nursing brain drain and its effects on patient safety. BioMed Central. 2020. https://doi.org/10.1186/s13756-02000719-4.

35. Kokoroko E, Sanda MA. Effect of workload on job stress of Ghanaian OPD nurses: the role of coworker support. Saf Health Work. 2019;10(3):341-6. https://doi.org/10.1016/j.shaw.2019.04.002.

36. Odonkor ST, Frimpong K. Burnout among healthcare professionals in Ghana: a critical assessment. Biomed Res Int. 2020;2020. https://doi.org/10.1155/ 2020/1614968.

37. Asiedu EEA, Annor F, Amponsah-Tawiah K, Dartey-Baah K. Juggling family and professional caring: role demands, work-family conflict and burnout among registered nurses in Ghana. Nursing Open. 2018;5(4):611-20. https:// doi.org/10.1002/nop2.178.

38. Lartey JKS, Osafo J, Andoh-Arthur J, Asante KO. Emotional experiences and coping strategies of nursing and midwifery practitioners in Ghana: a qualitative study. BMC Nurs. 2020;19(1):1-12. https://doi.org/10.1186/s12912020-00484-0.

39. Service GS. 2010 population and housing census report. Ghana Statistical Service; 2014. 
40. Service GH. Ghana health service 2014 annual report. Ghana: Ghana Health Service Accra; 2015.

41. Ogata Y, Sasaki M, Yumoto Y, Yonekura Y, Nagano M, Kanda K. Reliability and validity of the practice environment scale of the nursing work index for Japanese hospital nurses. Nursing Open. 2018;5(3):362-9. https://doi.org/10. 1002/nop2.148.

42. Lake ET, Sanders J, Duan R, Riman KA, Schoenauer KM, Chen Y. A metaanalysis of the associations between the nurse work environment in hospitals and 4 sets of outcomes. Med Care. 2019;57(5):353. https://doi.org/ 10.1097/MLR.0000000000001109.

43. Al-Hamdan Z, Manojlovich M, Tanima B. Jordanian nursing work environments, intent to stay, and job satisfaction. J Nurs Scholarsh. 2017; 49(1):103-10. https://doi.org/10.1111/jnu.12265.

44. Riley MR, Mohr DC, Waddimba AC. The reliability and validity of three-item screening measures for burnout: evidence from group-employed health care practitioners in upstate New York. Stress Health. 2018;34(1):187-93. https://doi.org/10.1002/smi.2762.

45. Hamby S, Grych E and Banyard, 2013 - Google Search. Available from: https://www.google.com/search?client=firefox-b-d\&q=hamby\%2C+grych+ and+banyard\%2C+2013. [cited 2020 Jun 16].

46. Hamby S, Taylor E, Smith A, Blount Z. Resilience portfolio questionnaire manual: scales for youth. Sewanee: Life Paths Research Center; 2018. http:// hdl.handle.net/20.500.11990/1704.

47. Trinchera L, Marie N, Marcoulides GA. A distribution free interval estimate for coefficient alpha. Struct Equation Model. 2018;25(6):876-87. https://doi. org/10.1080/10705511.2018.1431544.

48. Khamisa N, Peltzer K, llic D, Oldenburg B. Effect of personal and work stress on burnout, job satisfaction and general health of hospital nurses in South Africa. Health SA Gesondheid. 2017;22(1):252-8. https://doi.org/10.4102/ hsag.v22i0.1011.

49. Hailay A, Aberhe W, Mebrahtom G, Zereabruk K, Gebreayezgi G, Haile T. Burnout among nurses working in Ethiopia. Behav Neurol. 2020;2020. https://doi.org/10.1155/2020/8814557.

50. Ugwu LI, Enwereuzor IK, Fimber US, Ugwu DI. Nurses' burnout and counterproductive work behavior in a Nigerian sample: the moderating role of emotional intelligence. Int J Afr Nurs Sci. 2017;7:106-13. https://doi.org/ 10.1016/j.jjans.2017.11.004.

51. Koy V, Yunibhand J, Angsuroch Y, Fisher ML. Relationship between nursing care quality, nurse staffing, nurse job satisfaction, nurse practice environment, and burnout: literature review. Int J Res Med Sci. 2017;3(8): 1825-31. https://doi.org/10.18203/2320-6012.ijrms20150288.

52. Cramer E, Hunter B. Relationships between working conditions and emotional wellbeing in midwives. Women Birth. 2019;32(6):521-32. https:// doi.org/10.1016/j.wombi.2018.11.010.

53. Olsen E, Bjaalid G, Mikkelsen A. Work climate and the mediating role of workplace bullying related to job performance, job satisfaction, and work ability: a study among hospital nurses. J Adv Nurs. 2017;73(11):2709-19. https://doi.org/10.1111/jan.13337.

54. Fortunatti CP, Palmeiro-Silva YK. Effort-reward imbalance and burnout among ICU nursing staff: a cross-sectional study. Nurs Res. 2017:66(5):410-6. https://doi.org/10.1097/NNR.0000000000000239.

55. Abdul-Rahaman $\mathrm{G}$. The impact of monetary compensation on employee retention in Ghana Health Service: a case study of Ghana Health Service in Central Region [PhD Thesis]. 2016. http://hdl.handle.net/123456789/9108.

56. Nwankwo C, Okeke CP, Okeke OJ. Impact of motivation on the psychological wellbeing of nurses in Enugu Metropolis. Int J Acad Res Psychol. 2018;5(1):1-14. https://doi.org/10.6007/IJARP/v5-i1/4756.

57. Arrogante O. Mediator effect of resilience between burnout and health in nursing staff. Enfermeria Clin. 2013;24(5):283-9. https://doi.org/10.1016/j. enfcli.2014.06.003.

58. Ayalew F, Kibwana S, Shawula S, Misganaw E, Abosse Z, Van Roosmalen J, et al. Understanding job satisfaction and motivation among nurses in public health facilities of Ethiopia: a cross-sectional study. BMC Nurs. 2019;18(1):46. https://doi.org/10.1186/s12912-019-0373-8.

59. White EM, Aiken LH, McHugh MD. Registered nurse burnout, job dissatisfaction, and missed care in nursing homes. J Ame Geriatr Soc. 2019; 67(10):2065-71. https://doi.org/10.1111/jgs.16051.

60. Coetzee SK, Laschinger HK. Toward a comprehensive, theoretical model of compassion fatigue: a $n$ integrative literature review. Nurs Health Sci. 2018; 20(1):4-15. https://doi.org/10.1111/nhs.12387.
61. McHugh MD, Kang XL, Brom H, Lasater KB. Large-scale interventions to create hospital work environments that enhance nurse-physician teamwork Los Angeles: SAGE Publications Sage CA; 2020. https://doi.org/10.1177/ 0193945919896082.

62. Laschinger HKS, Borgogni L, Consiglio C, Read E. The effects of authentic leadership, six areas of worklife, and occupational coping self-efficacy on new graduate nurses' burnout and mental health: a cross-sectional study. Int J Nurs Stud. 2015;52(6):1080-9. https://doi.org/10.1016/j.jjnurstu.2015.03.002.

63. Van Bogaert P, Peremans L, Van Heusden D, Verspuy M, Kureckova V, Van de Cruys $Z$, et al. Predictors of burnout, work engagement and nurse reported job outcomes and quality of care: a mixed method study. BMC Nurs. 2017;16(1):5. https://doi.org/10.1186/s12912-016-0200-4.

64. Smollan RK. Learning to cope with stressful organisational change. Int J Work Organ Emot. 2017;8(2):148-67. https://doi.org/10.1504/IJWOE.2017. 086461.

65. Zhang M, Wang W, Millar R, Li G, Yan F. Coping and compromise: a qualitative study of how primary health care providers respond to health reform in China. Human Resour Health. 2017;15(1):1-12. https://doi.org/10. 1186/s12960-017-0226-Z

\section{Publisher's Note}

Springer Nature remains neutral with regard to jurisdictional claims in published maps and institutional affiliations.
Ready to submit your research? Choose BMC and benefit from:

- fast, convenient online submission

- thorough peer review by experienced researchers in your field

- rapid publication on acceptance

- support for research data, including large and complex data types

- gold Open Access which fosters wider collaboration and increased citations

- maximum visibility for your research: over $100 \mathrm{M}$ website views per year

At $\mathrm{BMC}$, research is always in progress.

Learn more biomedcentral.com/submissions 